\title{
超音波音響測深機にあらわれる偽底像に就て
}

\section{Fundamental researches of the Deep Scattering \\ Layer that scatters ultra-sonic sounds}

\section{熊 凝 武 晴 (東京水産大学)}

The Deep scattering Iayer (DSL) rises to the surface at sundown and sinks down against sunrise.

So far it has not heen pcsible to allege any physical discontinuity at present known in navigational circles as an explanation of the phenomenon. On the other hand, as numerous marine organisms show uertical variations of immersion in connection with light, most authorities agree that this scattering Iayer must be formed by concertrated groups of living organisms.

In this article, we studied about the fundamental refraction of ultra-sonic sound to be cause to the difference of temperature and density of sea water, or the groups of livingplanktons.

\section{1. 緒亭}

超音波音響測深機の記録にあらわれる偽底像（Deep Scattering Iayer. DSL）の成因，性状 並に変化に就ては色々な研究が行われている.DSLは超音波の反射の結果として記録紙上又はオ ツシログラン゙上に表われる晲象で，徉来は $1 / 20 \sim 1 / 10$ 秒程度の音波の発振の際に，游洋300 460 米の梁度飞認められて居つそのであるが, 現今航海用に用いられる 1/800 1/1000 秒程度の超音波 の発振の際にも充分䜅められるが，前者に比して深度の浅ん DSL が観測されてんる：或るもの

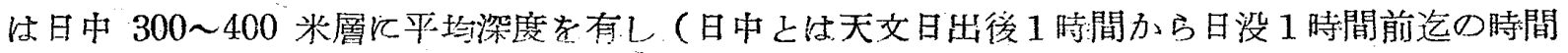
をい5）て存在し, 或るものは日没には表面に上昇し, 日出には再び下降し, 日中前述の平均 深度保つて深海炕存在する。

1.1 DSL が下降する際の重值的沈降速度は上昇速度より速ん。

1.2 日中の間は完全に連続して水平に近く, その厚さ恃 100 米江近い昜命があるが, 掋散勢 力俍つて推定すると, その濃度は常に変化してんる。

1.3 DSL の発生は海洋の深度沈無関係である。

1.4 DSL は季節的には著しん変化はない。

1.5 乙実験は別府湾, 相摸湾, 駿河湾, 館山湾, 日本南海, ベーリング海及び中部太平洋 で行つをが上記のような現象が起つている。1942年 DSLをとなえられてからの調查では 大西洋，雨栖洋等殆に゙地域的飞関係なく，湖沼に於ても出現してている。

1.6DSL 中から徽生物，稚魚等の採集も行われ，殊に甲豰類の稚魚及びコペポーダ采のプ ランタトンが多数存在してんる。




徽生物の集団層の反射と両様に考えられるので；それ等の組成を基礎的に究明するをめの実験と して，物理的，生物的要因の超音波伝播並に反射に及壮寸效果老調べるととにした。

\section{2. 実 験 装 置}

使 用 器 械

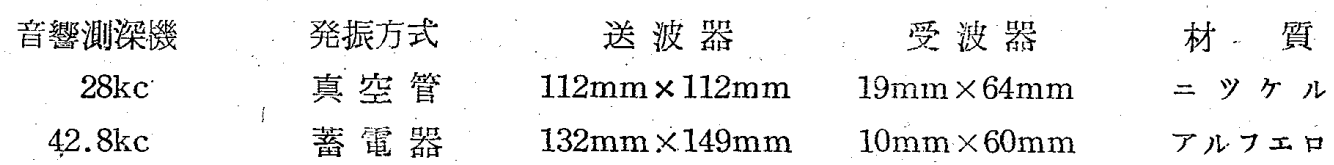

水 榑

$24.0 \mathrm{~m} \times 0.5 \mathrm{~m} \times 0.5 \mathrm{~m}$ 木製水槽で浮水を用いた。

水 槽 特 性

この水槽に於ける超音波伀播特性は平面波亡考えられ，資料槽は伝播特性の平坦である送 波器から21米の㚮を使用した。

\begin{tabular}{|c|c|c|c|c|c|c|c|c|c|c|}
\hline 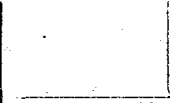 & $\underbrace{\text { 践深機 }}$ & 14 & 15 & 16 & 17 & 18 & 19 & 20 & 21 & 22 \\
\hline 逗接波音压 & $28 \mathrm{kc}$ & 75 & 74 & 71 & 73 & 72 & 72 & 72 & 72 & 73 \\
\hline$\left(M_{D}\right)$ & $42.8 \mathrm{kc}$ & 66 & 65 & 63 & 60 & 61 & 62 & 61 & 62 & 60 \\
\hline
\end{tabular}

距離＼cjkstart送波器と受波器との間の距離

\section{資 料槽}

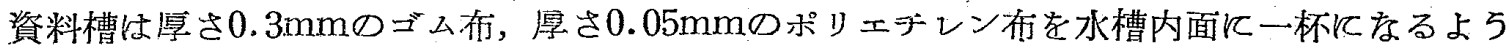

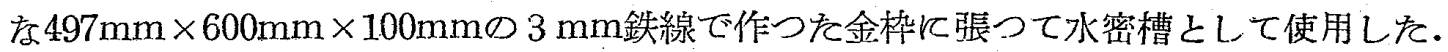

資料槽の反射損失

\begin{tabular}{|c|c|c|c|c|c|c|c|c|c|}
\hline 資料槽 & \multicolumn{2}{|c|}{ 送受波器闁の距紸。 } & 15.5 & 16.0 & 16.5 & 17.0 & 17.5 & 18.0 & 反射摃失 \\
\hline \multirow{2}{*}{$\begin{array}{l}\text { ポン } \\
\text { y惁 } \\
x \\
\text { 千 } \\
\text { L }\end{array}$} & $28 \mathrm{kc}$ 振動子 & $\begin{array}{l}M_{D} \mathrm{dk} \\
M_{R}\end{array}$ & $\begin{array}{l}77 \\
19\end{array}$ & $\begin{array}{l}77 \\
19\end{array}$ & $\begin{array}{l}78 \\
23\end{array}$ & $\begin{array}{l}77 \\
19\end{array}$ & $\begin{array}{l}76 \\
19\end{array}$ & $\begin{array}{l}77 \\
24\end{array}$ & $58 \mathrm{dt}$ \\
\hline & $42.8 \mathrm{kc} . " \prime$ & $M_{D} \mathrm{db}$ & $\begin{array}{r}65 \\
\mathrm{G}\end{array}$ & $\begin{array}{r}66 \\
.9\end{array}$ & $\begin{array}{r}67 \\
8\end{array}$ & $\begin{array}{l}67 \\
10\end{array}$ & $\begin{array}{l}68 \\
10\end{array}$ & $\begin{array}{l}68 \\
10\end{array}$ & $57 " \prime$ \\
\hline 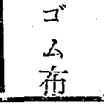 & $28 \mathrm{kc} \quad$ & $\begin{array}{l}M_{D} \\
M_{R} \\
\mathrm{db}\end{array}$ & $\begin{array}{r}78 \\
24 \\
\end{array}$ & $\begin{array}{l}77 \\
24\end{array}$ & $\begin{array}{l}79 \\
27\end{array}$ & $\begin{array}{l}78 \\
21\end{array}$ & $\begin{array}{l}77 \\
24 \\
\end{array}$ & $\begin{array}{l}75 \\
24\end{array}$ & $54 / \prime$ \\
\hline
\end{tabular}

送波器を 0 米に, 資料槽を21米の処㯰いて, 受波器を15.5 18.0米間に移動させて測定 した.

$M_{D}$ 直接波音压

$M_{R}$ 反射波音压

我りエチレン有 $(0.05 \mathrm{~mm})$ 透過損失 $1 \mathrm{db}$

$\exists$ A 有 $(0.3 \mathrm{~mm})$ 透過損失 $2 \mathrm{db}$

ポリエチレン資料槽の反射損失は上表の上らであるから今回の実験《は充分使用可能とし

て使用した。

\section{3. 測 定}

水槽（断面 $24.5 \mathrm{~m} \times 0.5 \mathrm{~m} \times 0.5 \mathrm{~m}$ ) 飞淡水を満し，一端に送受波器を並列に設け，てれから21 
米の処に資料槽を插入して，置換法に位つて反射損失を求むる方法によつた．資料槽内が水槽と

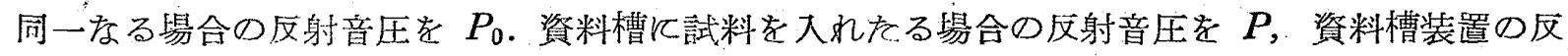
射損失を $L_{0}$ とすると

求导る反射音压 $L=L_{0}-\left(P-P_{0}\right)$

\section{1. 物理的変化飞よる反射損失}

\subsection{1. 水の温度差飞低る反射損失}

海洋の潮目或は湧昇流のある附近は高低二温度が複雑飞重つて, 温度傾度は異常状態呈呈す る. 勿論斯の如き処に值類又は稚魚が狭水性から集合することが多い．との温度差に依つて反

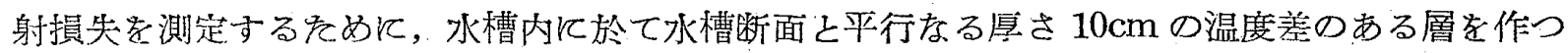


温湯を入れて，ポリエチレン布の外部につく気胞を 完全飞除去し, $28 \mathrm{kc}, 42.8 \mathrm{kc}$ の音響測深機飞低つ て Fig 1. の上5に温度差飞対する反射高压を測う

/て. 次式によつて第1表及び Fig 20 吥射

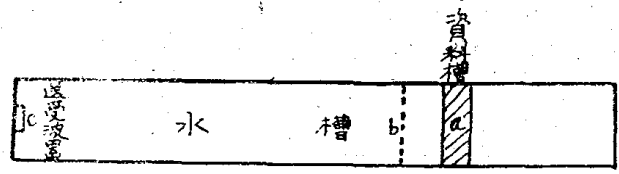
Fig ' 損失堂求めを。

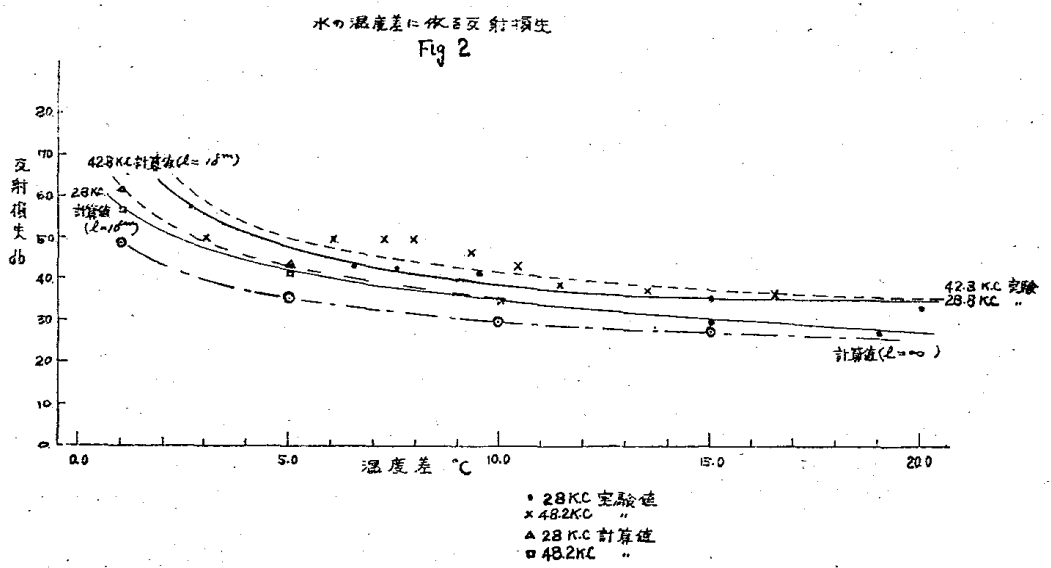

$\frac{B^{2}}{A^{2}}=\frac{\left(\frac{\rho C \cos \theta_{1}}{\rho_{1} C_{1} \cos \theta}-\frac{\rho_{1} C_{1} \cos \theta}{\rho C \cos \theta_{1}}\right)^{2}}{4 \cot ^{2} \frac{2 \pi 1}{\lambda_{1}} \cos \theta_{1}+\left(\frac{\rho C \cos \theta_{1}}{\rho_{1} C_{1} \cos \theta}+\frac{\rho_{1} C_{1} \cos \theta}{\rho C \cos \theta_{1}}\right)^{2}}$

$A^{2}$ 入射勢力

$B^{2}$ 反射勢力

$\rho, C$ 媒質の密度，音速

$\rho_{1} C_{\mathrm{j}} \lambda_{1}$ 物筫の密度, 音速, 波長

\section{$\theta$ 入射角}

$\theta_{1}$ 反射角

$l \quad$ 物質の厚さ

$\gamma$ 音压反射率

$$
\begin{aligned}
& \theta=\theta_{1}=0 \text { 亡する } \\
& \gamma=\sqrt{\frac{\left(\frac{\rho c}{\rho_{1} c_{1}}-\frac{\rho_{1} c_{1}}{\rho c}\right)^{2}}{4 \cot ^{2}-\frac{2 \pi l}{\lambda_{1}}+\left(\frac{\rho c}{\rho_{1} c_{\mathrm{I}}}+\frac{\rho_{1} c_{1}}{\rho c}\right)}}
\end{aligned}
$$




$$
L=20 \log _{10} \frac{1}{\gamma}
$$

第 1 韹

\begin{tabular}{|c|c|c|c|c|c|c|c|c|}
\hline 周波数。 & $\begin{array}{ll}t_{a} & \\
& \mathrm{C}^{\circ}\end{array}$ & $\begin{array}{ll}t_{b} & \\
& C^{\circ}\end{array}$ & $t_{C} \mathrm{C}^{\mathrm{O}}$ & $T\left(t_{a}-t_{b}\right)$ & $M_{R}$ & $\begin{array}{ll}L & \\
& \mathrm{db}\end{array}$ & $\%$ & $L_{o}{ }_{\mathrm{dh}}$ \\
\hline \multirow{9}{*}{$28 \mathrm{kc}$} & 29.5 & 10.5 & 10.4 & 19.0 & 45 & 34 & 1.99 & 58 \\
\hline & 25.5 & 10.5 & 10.4 & 15.0 & 43 & 36 & 1.58 & 58 \\
\hline & 22.0 & 10.5 & 10.4 & 11.5 & 38 & 41 & 0.98 & 58 \\
\hline & 20.0 & 10.5 & 10.4 & 9.5 & 37 & 42 & 0.79 & 58 \\
\hline & 18.0 & 10.5 & 10.4 & 7.5 & 36 & 43 & 0.70 & 58 \\
\hline & 17.0 & 10.5 & 10.4 & 6.5 & 36 & 43 & 0.70 & 58 \\
\hline & 15.5 & 10.5 & 10.4 & 5.0 & 35 & 44 & 0.63 & 58 \\
\hline & 13.1 & 10.5 & 10.4 & 2.6 & 22 & 57 & 0.14 & 58 \\
\hline & 10.5 & 10.5 & 10.5 & 0.0 & 21 & 58 & 0.12 & 58 \\
\hline \multirow{10}{*}{$42.8 \mathrm{kc}$} & 26,5 & 10.6 & 9.8 & 16.5 & 37 & 36 & 1.58 & 57 \\
\hline & 23.6 & 10.1 & 9.8 & 13.5 & 35 & 38 & 1.26 & 57 \\
\hline & 21.5 & 10.1 & 9.8 & 11.4 & 34 & 39 & 1.12 & 57 \\
\hline & 20.6 & 10.2 & 9.8 & .10 .4 & 29 & 44 & 0.63 & 57 \\
\hline & 19.7 & 10.3 & 9.8 & 9.3 & 26 & 47 & 0.44 & 57 \\
\hline & 18.2 & 10.3 & 10.2 & $7 . \mathrm{g}$ & 23 & 50 & 0.31 & 57 \\
\hline & 17.5 & 10.3 & 10.2 & 7.2 & 23 & 50 & 0.31 & 57 \\
\hline & 16.5 & 10.5 & 10.2 & 6.0 & 23 & 50 & 0.31 & 57 \\
\hline & 14.0 & 10.5 & 10.2 & 3.5 & 23 & 50 & 0.31 & 57 \\
\hline & 10.5 & 10.5 & 10.5 & 0.0 & 16 & 57 & 0.14 & 57 \\
\hline
\end{tabular}

\subsection{2. 水の㟵度差飞佂る反射損失}

海洋に於て密度の異る水塊が相接する場合を考光，同一水槽で同一条件のも上に送受波器よb

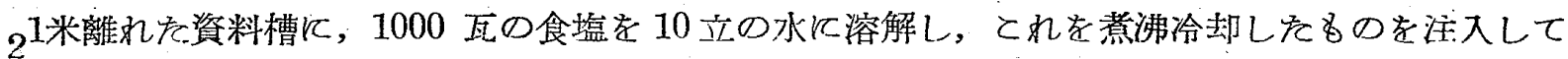
7 段階飞異る密度の液を作 $b$ ，水槽の水との密度差飞依る反射損失を測つて第 2 表及び Fig $3 \infty$ 值老得存。

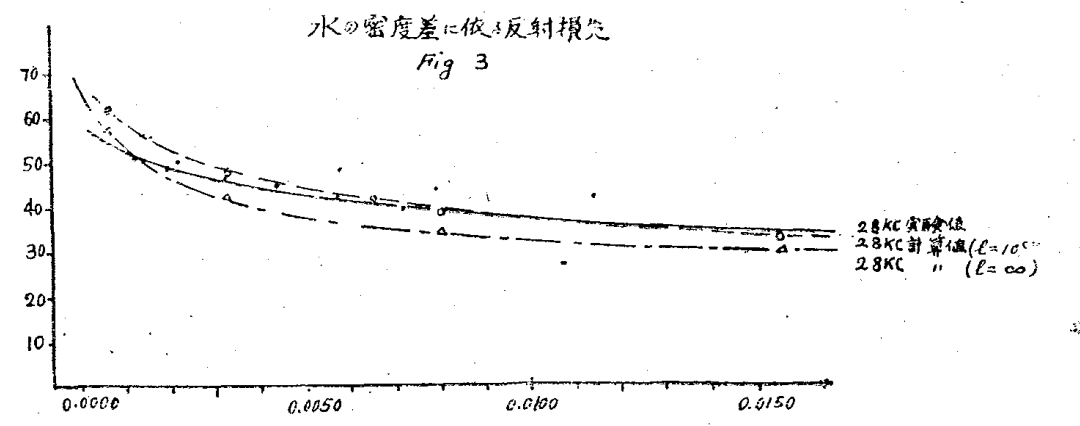

\section{$\rho$ 水槽内水の此重}

$\rho_{1} \quad$ 資料䄚内食塩水の比重

$M_{R}$ 反射波音压

$L_{o}$. 反射損失

$L$ 反射音压 
第 2 表

\begin{tabular}{|c|c|c|c|c|c|c|c|c|}
\hline 周波数。 & 水槽温度 & $\mathrm{g} / \mathrm{cm}^{3}$ & $\begin{array}{c}\rho_{1} \\
\mathrm{~g} / \mathrm{cm}^{3}\end{array}$ & $\begin{array}{l}\rho_{1}-\rho \\
\mathrm{g} / \mathrm{cm}^{\mathrm{s}}\end{array}$ & $M_{R}{ }_{\mathrm{db}}$ & $\begin{array}{ll}L & \\
& \\
\mathrm{db}\end{array}$ & $\%$ & $L_{o}^{L_{o}}$ \\
\hline \multirow{7}{*}{$28 \mathrm{kc}$} & \multirow{7}{*}{$7.4^{\circ} \mathrm{C}$} & \multirow[t]{7}{*}{0.9999} & 0.9999 & 0.0000 & 26 & 54 & 0.19 & 54 \\
\hline & & & 1.0019 & 0.0020 & 31 & 49 & 0.35 & 54 \\
\hline & & & 1.0032 & 0.0033 & 33 & 47 & 0.44 & 54 \\
\hline & & & 1.0043 & 0,0044 & 35 & 45 & 0.56 & 54 \\
\hline & & & 1.0057 & 0.0058 & 37 & 43 & 0.70 & 54 \\
\hline & & & 1.0071 & 0.0072 & 40 & 40 & 1.00 & 54 \\
\hline & & & 1.0106 & 0.0107 & 52 & 28 & 4.46 & 51 \\
\hline \multirow{6}{*}{$28 \mathrm{kc}$} & \multirow{6}{*}{$3.8^{\circ} \mathrm{C}$} & \multirow[t]{6}{*}{1.0000} & 1.0000 & 0.0000 & 23 & 54 & 0.99 & 54 \\
\hline & & & 1.0013 & 0.0013 & 26 & 51 & 0.28 & 54 \\
\hline & & & 1.0022 & 0.0022 & 27 & 50 & 0.31 & 54 \\
\hline & & & 1.0058 & 0.0058 & 28 & 49 & 0.35 & 54 \\
\hline & & & 1.0079 & 0.0079 & 32 & 45 & 0.56 & 54 \\
\hline & & & 1.0114 & 0.0114 & 33 & 44 & 0.63 & 54 \\
\hline
\end{tabular}

3.2. プランクトンが超音波伝播化及将す影響

游洋中のプランクトン，塵芥，その他の有機物が超音波の伝播に影響して，その密度と反射損 失との関係を調べる為に，水槽中の資料槽にプランクトンの混合一定量を入れ，攪拌して均一密 度層を作つた. 3.1 .2 と同様を方法で反射損失を測定して第三表及び Fig 4 の值を得を.

資料は浦賀港沖で採集したもので，動物性 7 ，植物性 3 の劃会飞混合されそものである。採集 した総量の1/万づつをプラン゙クトンネツトに移して真水で洗ん，壏水を取除んをものを資料槽に注

第 3 表

\begin{tabular}{|c|c|c|c|c|c|c|c|c|}
\hline \multirow{2}{*}{$V_{\mathrm{cl}}$} & \multicolumn{2}{|c|}{$M_{R} \quad \mathrm{db}$} & \multicolumn{2}{|c|}{$L-\mathrm{db}$} & \multicolumn{2}{|c|}{$\%$} & \multicolumn{2}{|l|}{$L_{o}$} \\
\hline & $28 \mathrm{kc}$ & $42.8 \mathrm{kc}$ & $28 \mathrm{kc}$ & $42.8 \mathrm{kc}$ & $28 \mathrm{kc}$ & $42.8 \mathrm{kc}$ & $28 \mathrm{kc}$ & $42.8 \mathrm{kc}$ \\
\hline 0 & 23 & 19 & 58 & 57 & 0.112 & 0.141 & 58 & 57 \\
\hline 47.4 & 28 & 25 & 53 & 51 & 0.223 & 0.281 & 58 & 57 \\
\hline 94.8 & 29 & 27 & 52 & 49 & 0.251 & 0.354 & 58 & 57 \\
\hline 142.2 & 30 & 28 & 51 & 48 & 0.281 & 0.398 & 58 & 57 \\
\hline 189.6 & 28 & 29 & 53 & 47 & 0.223 & 0.446 & 58 & 57 \\
\hline 237.0 & 28 & 29 & 53 & 48 & 0.223 & 0.396 & 58 & 57 \\
\hline
\end{tabular}




入して，一椂に攪拌してて币射損失を測定した。資料槽の水をプランクトンネツトル移して濾した プランクトンを，フォルマリンで固起後 48 時間沈澱させて，其の容量を測つて資料慒の測资㭙 の密度を計算した。

$$
\begin{array}{ll}
M_{R} & \text { 反射波音区 } \\
V & \text { プランクトン沈搌容積 }
\end{array}
$$

\section{4. 考察}

以上の基礎的実験結果飞依る之水温，密度の変化層に於ける超音波の反射状況は

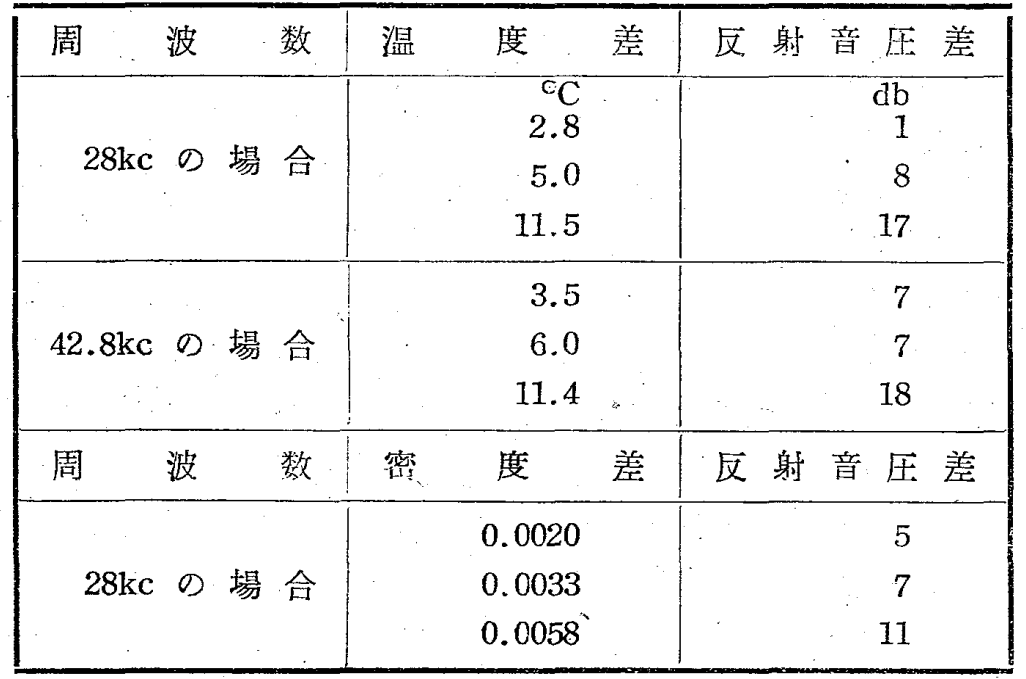

\begin{tabular}{|c|c|c|c|}
\hline 周 波 数 & 湿 & 度 & 反射音压羑 \\
\hline \multirow{3}{*}{$28 \mathrm{kc}$ の.場 合 } & $\begin{array}{r}\text { c.c } \\
47.4\end{array}$ & & $\begin{array}{r}\mathrm{db} \\
5\end{array}$ \\
\hline & 94.8 & & 6 \\
\hline & 142.2 & & 7 \\
\hline \multirow{3}{*}{$22.8 \mathrm{kc} の$ 場 合 } & 47.4 & & 6 \\
\hline & 94.8 & & 8 \\
\hline & 142.2 & & 9 \\
\hline
\end{tabular}

プランクトンKよる超音波の反射状況は

反射状況から DSL を見ると，浅層に於ては温度差に関しては $5^{\circ} \mathrm{C}$ 前後，密度に関しては 0.0033 程度が先づ考えられ，プランクトンは $140 \mathrm{c} . \mathrm{c}$ の含有程度が先づ考えられるのである.


のである.従つて DSL の生態を判然たらしめるには音压以外の方法を考え放ばをらぬのであ る.

次飞興昧ある問題は日照，即ち水中に於ける照度の変化飞供つて生和るDSL の浮沈現象であ

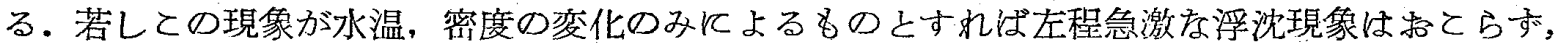

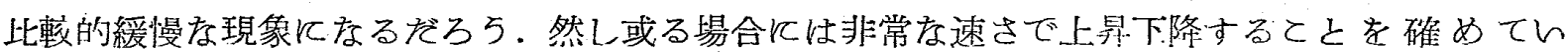
る。昭和28年 8 月小笠原列島附近で行つた実験

$$
\text { 昭和28年 } 8 \text { 月 } 29 \text { 日 } \quad \begin{array}{ll}
27^{\circ}-34^{\prime} N \\
146-15 E
\end{array}
$$

水 温 $28^{\circ} \sim 30^{\circ} \mathrm{C}$ 


\section{月 命 15 日 (最高及度 $53^{\circ}$ ) \\ 日 没 $18 \mathrm{~h}-26 \mathrm{~m}$ (常用)}

常用薄明の終り 18h-54m

当日，日没頃 35〜45 米深度間飞 10〜15 米厚さの DSL を発見，常用薄明が了る頃，太㓌高度 22 度で，との間に於ける上下の移動には蹎著度変化を見なかつたが，薄明後に月の高度が2 $/ 3 に$ 達する迄の間に於て次第に下降し約 20 米程沈九だ。然し最高々度 $2 / 3 を$ 過を゙を頃から DSL は浮


位置にあつた．太陰が頂点に達した後は前と対照的に変化した。

次の例は昭和 28 年 10 月 25 日館山湾に於ての笑験

$\begin{array}{cccccc}\text { 日 } & \text { 時 } & \text { 深度 } & \text { 采さ } & \text { 水深 } & \text { 速度 } \\ \text { 10月28日 } & 1623 & \text { DSL発見23米 } & 20 \text { 米 } & & \\ & 1653 & 16 & 20 & & \\ 1655 & 10 & 24 & 110 \text { 米 } & 0.4 \text { 米/分 } \\ 1703 & 13 & 12 & & \\ 1710 & 10 & 17 & & \\ 1731 & 4 & 13 & & \\ 1742 & 3 & 12 & & \end{array}$


のプランクトン採集を行つたところ，多数の動物性プラクトン及びェどの稚魚を得を.

前例は照度に依るプランクトンの浮沈景降と考えられ，後例は一般現象と考えられる。

\section{5. 結}

物理現象，生物現象乞も記録上で区别は困難である．水中照度に低つて比較的速に DSL の厚 さが変化しつつ上下動するものは，委づ微生物によるもの上推是出来るであるう。との点に関し ては P.F. Smith, Hersey 其他の人々の報告と一致する.物理的要因に低るものは 1947〜1949 年頃となえられたが，最近では生物要因とする説が或る部分を叔めているんべれにしても DSL は超音波音響測深機の発振勢力に比例して，顕著に記録上飞現われるものであるから，航 海保安用に特に位置を誤認せざるよう注意が必要であろう。 